OPEN ACCESS

Edited by:

Mathieu Gruet,

Université de Toulon, France

Reviewed by:

Zoe Louise Saynor,

University of Portsmouth,

United Kingdom

Marcelo Coertjens,

Federal University of Piauí, Brazil

${ }^{*}$ Correspondence:

Tom Citherlet

toom@hotmail.ch

Specialty section:

This article was submitted to

Elite Sports and Performance

Enhancement,

a section of the journal

Frontiers in Sports and Active Living

Received: 26 April 2021

Accepted: 02 July 2021

Published: 25 August 2021

Citation:

Citherlet T, Crettaz von Roten F,

Kayser B and Guex K (2021) Acute

Effects of the Wim Hof Breathing Method on Repeated Sprint Ability: A

Pilot Study.

Front. Sports Act. Living 3:700757.

doi: 10.3389/fspor.2021.700757

\section{Acute Effects of the Wim Hof Breathing Method on Repeated Sprint Ability: A Pilot Study}

\author{
Tom Citherlet ${ }^{1 *}$, Fabienne Crettaz von Roten ${ }^{1}$, Bengt Kayser ${ }^{1}$ and Kenny Guex ${ }^{2,3}$ \\ ${ }^{1}$ Institute of Sport Sciences, University of Lausanne, Lausanne, Switzerland, ${ }^{2}$ School of Health Sciences, University of \\ Applied Sciences and Arts Western Switzerland, Lausanne, Switzerland, ${ }^{3}$ Swiss Athletics, Haus des Sports, Ittigen, \\ Switzerland
}

The Wim Hof breathing method (WHBM) combines periods of hyperventilation (HV) followed by voluntary breath-holds $(\mathrm{BH})$ at low lung volume. It has been increasingly adopted by coaches and their athletes to improve performance, but there was no published research on its effects. We determined the feasibility of implementing a single WHBM session before repeated sprinting performance and evaluated any acute ergogenic effects. Fifteen amateur runners performed a single WHBM session prior to a Repeated Ability Sprint Test (RAST) in comparison to voluntary HV or spontaneous breathing (SB) (control) in a randomized cross-over design. Gas exchange, heart rate, and finger pulse oxygen saturation $\left(\mathrm{SpO}_{2}\right)$ were monitored. Despite large physiological effects in the $\mathrm{SpO}_{2}$ and expired carbon dioxide $\left(\mathrm{VCO}_{2}\right)$ levels of both $\mathrm{HV}$ and WHBM, no significant positive or negative condition effects were found on RAST peak power, average power, or fatigue index. Finger $\mathrm{SpO}_{2}$ dropped to $60 \pm 12 \%$ at the end of the $\mathrm{BHs}$. Upon the last $\mathrm{HV}$ in the WHBM and $\mathrm{HV}$ conditions, end-tidal $\mathrm{CO}_{2}$ partial pressure $\left(\mathrm{PETCO}_{2}\right.$ ) values were $19 \pm 3$ and $17 \pm 3 \mathrm{mmHg}$, indicative of respiratory alkalosis with estimated arterial $\mathrm{pH}$ increases of +0.171 and of +0.181 , respectively. Upon completion of RAST, 8 min cumulated expired carbon dioxide volumes in the WHBM and HV were greater than in SB, suggesting lingering carbon dioxide stores depletion. These findings indicate that despite large physiological effects, a single WHBM session does not improve anaerobic performance in repeated sprinting exercise.

Keywords: Wim Hof breathing method, hyperventilation, apnea, RAST, anaerobic performance

\section{INTRODUCTION}

Wim Hof is a Dutch athlete, nicknamed "Iceman" for his ability to withstand freezing temperatures. He has accumulated 20 "world records" for feats such as standing in a container while covered with ice cubes for $2 \mathrm{~h}$, climbing Mount Kilimanjaro in shorts, swimming $60 \mathrm{~m}$ underneath ice, and running a half marathon barefoot on snow and ice north of the Arctic Circle (Hof, 2020c). $\mathrm{He}$ attributes these feats to training with his Wim Hof Method (WHM). This is a combination of breathing exercises [Wim Hof breathing method (WHBM): periods of hyperventilation (HV) followed by voluntary breath-holds (BH) at low lung volume (Hof, 2020b)], repeated exposure to cold, and mental commitment (Hof, 2020e). The WHM allegedly provides benefits such as stress reduction, enhanced creativity, more focus and mental clarity, better sleep, improved cardiovascular health, and improved exercise performance (Hof, 2020b). The latter would include 
faster recovery from physical exertion, heightened focus and mental composure, and increased muscular endurance (Hof, 2020d).

Many athletes have adopted the WHM, such as the tennis player Novak Djokovic (Novak Djokovic on Instagram: @iceman_hof how did we do?..., 2021), the surfer Kelly Slater (Kelly Slater's Bizarre, Daredevil-Inspired Breathing Technique, 2021), the American football punter Steve Weatherford (Hof, 2020a), the rower Janneke van der Meulen (Hof, 2020d), the UFC fighter Alistair Overeem, and the big wave surfer Laird Hamilton (Hof, 2021).

While the WHM seems to present interesting benefits, there is virtually no published research on its effects on sport performance. However, studies have shown that HV, which is part of the WHBM, can improve anaerobic performance (Ziegler, 2002; Sakamoto et al., 2014; Jacob et al., 2015). HV induces hypocapnia and drives the reaction sequence $\mathrm{H}^{+}+$ $\mathrm{HCO}_{3}^{-} \leftrightarrow \mathrm{H}_{2} \mathrm{CO}_{3} \leftrightarrow \mathrm{H}_{2} \mathrm{O}+\mathrm{CO}_{2}$ more to the right, elevating blood $\mathrm{pH}$ (Saladin and Miller, 2004). This respiratory alkalosis may improve anaerobic performance by compensating exerciseinduced metabolic acidosis (Jacob et al., 2008). The effects on the performance of $\mathrm{HV}$, combined with $\mathrm{BH}$, as done in the WHBM, have not been investigated yet.

By itself, $\mathrm{BH}$ drives the reaction sequence $\mathrm{H}^{+}+\mathrm{HCO}_{3}^{-} \leftrightarrow$ $\mathrm{H}_{2} \mathrm{CO}_{3} \leftrightarrow \mathrm{H}_{2} \mathrm{O}+\mathrm{CO}_{2}$ more to the left, inducing a respiratory acidosis (Pflanzer, 2004). Thus, in the WHBM, the $\mathrm{BH}$-induced $\mathrm{CO}_{2}$ retention would counter the $\mathrm{HV}$-induced respiratory alkalosis. $\mathrm{BH}$ also triggers the so-called "diving response" (Foster and Sheel, 2005), which includes bradycardia, peripherical vasoconstriction, increased blood pressure, and contraction of the spleen (Dujic et al., 2011). The latter releases $\sim 100 \mathrm{ml}$ of concentrated red cells into the circulation, which may influence performance, even though most investigations did not find improvement in performance following apneas ( $\mathrm{Du}$ Bois et al., 2014; Sperlich et al., 2015; Yildiz, 2018).

Any effects of HV or the WHBM are expected to be shortlasting and most likely to occur in short duration anaerobic lactic type performance such as the Wingate test, which is a cycle ergometer test more specific to cycling-based sports. The development of the Repeated Ability Sprint Test (RAST) provides a reliable, valid (Zagatto et al., 2008), and practicable field test to determine running anaerobic power (Nick and Whyte, 1997). With $6 \times 35 \mathrm{~m}$ repeated sprints, the total running time is close to $30 \mathrm{~s}$, making the test comparable with the Wingate test. Times and body weight can be used to calculate maximal and average power outputs along with a fatigue index. Repeated high-intensity sprints cause substantial metabolic acidosis, contributing to muscular fatigue and metabolic output decline (Kairouz et al., 2013).

Therefore, the aims of this pilot study were to determine the feasibility of implementing the WHBM before sport performance and evaluate whether a single WHBM session provides any acute

Abbreviations: $\mathrm{BH}$, breath-hold; FI, fatigue index; HV, hyperventilation; RAST, repeated ability sprint test; RPE, rate of perceived exertion; RV, residual volume; $\mathrm{SB}$, spontaneous breathing; TLC, total lung capacity; WHBM, Wim Hof breathing method; WHM, Wim Hof method. ergogenic effects during repeated-sprint bouts. In addition to performance, physiological and psychological data were collected to allow a better global understanding of the WHBM.

\section{METHODS}

\section{Experimental Approach to the Problem}

We did a randomized, controlled three-way crossover pilot study to (1) assess the feasibility of pre-performance WHBM and (2) compare the acute effects of single sessions of the WHBM, HV, and SB on performance. Feasibility concerned recruitment, execution of the WHBM, and data collection. Performance was assessed with the RAST. Body mass and running times were used to calculate peak power, average power, and fatigue index (FI) (Nick and Whyte, 1997) to compare performance between conditions. Gas exchange, oxygen saturation (finger pulse oximetry), heart rate (HR), rate of perceived exertion (RPE), and responses to three questionnaires were collected to evaluate whether there were any differences in RAST performance between the breathing methods that would correlate with physiological changes.

\section{Participants}

Inclusion criteria included being a healthy regular runner (in base training for more than 3 years with 2 or more running training sessions per week) in order to limit variability in sprinting performance, being familiar with maximal sprinting, being an adult (18 years or older), and being male (to avoid influence from hormone level changes and to limit the total number of participants to be recruited). The participants were recruited through word of mouth and social media. Sixteen physical education students volunteered with one participant excluded because of an injury, resulting in a final sample size of 15 (72.4 $\pm 6.3 \mathrm{~kg}, 24.5 \pm 2.3$ years, $10.3 \pm 4.7$ training years, $7.6 \pm 2.5$ $\mathrm{h}$ /week training, $7.3 \pm 1.1$ peak sprint power in watt/kg; mean values \pm standard deviations).

\section{Procedures}

The experiments were performed in late summer 2020 on a covered $50 \mathrm{~m}$ tartan track ("La Pontaise," Lausanne, Switzerland, elevation $597 \mathrm{~m}$ ). Weather influenced ambient temperature, which was systematically measured. Once a week (same day, same time) for 4 weeks; each participant was seen by the same experimenter. The first meeting was used to answer questions and obtain written consent, to record demographic data, to collect a baseline running time with the control condition, and to familiarize the participants with the testing and the two breathing maneuvers to maximize reliability. The next three sessions were used to assess each method (WHBM, HV, and SB) in a balanced randomized order (computer-generated sequence). The participants were kept blinded to the results of the sprints until the end of the last session. They were instructed to maintain their usual diet and lifestyle during the study, to abstain from tobacco, coffee, alcohol, and ergogenic drugs the day of testing, and to abstain from any important exercise the day leading up to the test. 

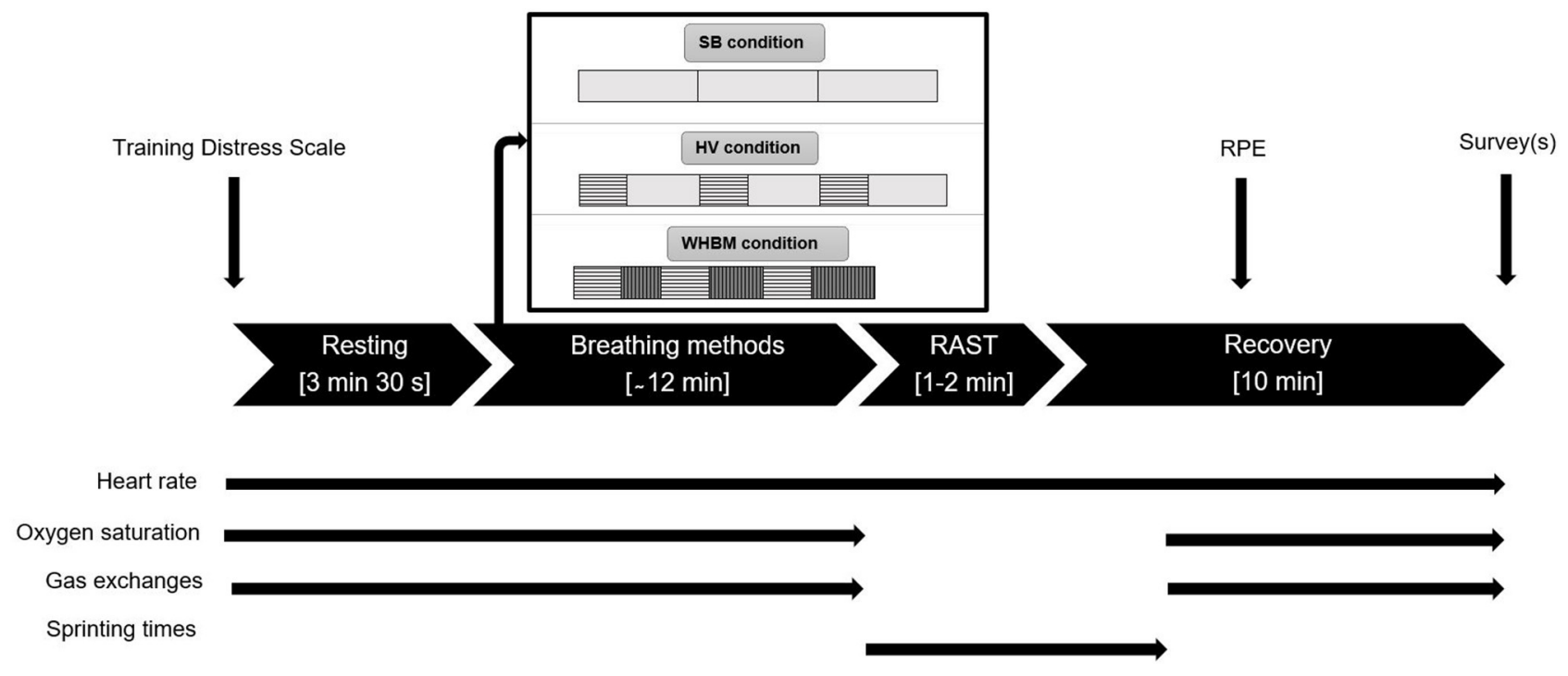

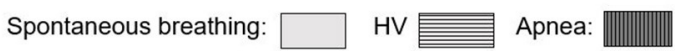

FIGURE 1 | Overview of the protocol. Thin straight black arrows indicate when different data collection occurred. Apnea rectangles length increases because the breath-holds (BHs) durations spontaneously increased.

Participants started each session with the same self-chosen warm-up. Then, they took a supine position on a floor mat and rested for $3 \mathrm{~min} 30 \mathrm{~s}$ for the acquisition of resting values before executing the specific breathing method (WHBM, HV, and $\mathrm{SB})$ while conserving the supine position. Then, after $10 \mathrm{~s}$, the participants prepared for the start of the RAST. The test involved performing $6 \times 35 \mathrm{~m}$ sprints with $10 \mathrm{~s}$ rests between sprints. The participants took a sprint 3-point stance start position $3 \mathrm{~s}$ before each sprint, waited for the "go" signal, and then performed allout sprints under strong verbal encouragement. The participants were instructed to perform each sprint as fast as possible and not use a pacing strategy. The timing was started manually and automatically stopped with photocells using an electronic timer (Witty, Microgate, Bolzano, Italy). Upon arrival, the participants immediately took their supine position again for $10 \mathrm{~min}$ of postsprint measurements.

\section{Breathing Methods}

The WHBM was performed using the audio guide on the WHM mobile app. The participants performed three cycles of the WHBM as prescribed by the official website (Hof, 2020b). One cycle consisted of hyperventilating for 30 breaths, defined as respiratory movements of maximum amplitude at the frequency given by the audio guide $(\sim 0.32 \mathrm{~Hz})$. This period lasted $\sim 1 \mathrm{~min}$ $30 \mathrm{~s}$. The participants then fully exhaled to residual volume (RV) and held their breath as long as possible $(\mathrm{BH})$. At breaking point, they inhaled to total lung capacity (TLC) and kept their breath for $15 \mathrm{~s}$ before starting the next cycle. $\mathrm{HV}$ was performed as in the WHBM, except that the $\mathrm{BH}$ times were substituted with $\sim 2$ min 30 s of spontaneous breathing (the prior estimated breath hold duration), for a total duration of $12 \mathrm{~min}$ for the breathing maneuvers. The control condition consisted of spontaneous breathing (SB) for $12 \mathrm{~min}$. Upon completion of the last cycle, the participants took off the face mask and the finger oximeter and prepared for RAST (see Figure 1).

\section{Repeated Sprint Ability}

Performance was assessed with the RAST. Peak power and average power were obtained using the equation Power $=$ (bodymass $\times$ distance $\left.^{2}\right) /$ time $^{3}$ and the FI was calculated using the equation FI= (Peak Power-Min Power) / Total Sprint Time (Nick and Whyte, 1997).

\section{Physiological Monitoring}

Except during RAST, gas exchange was monitored breath-bybreath throughout the experiment with a portable metabolic device (K5, COSMED, Rome, Italy) and a face mask. The device was calibrated before each test using a $3 \mathrm{~L}$ syringe and gas mixtures of known concentration. Delay calibration and scrubber testing were done regularly. Oxygen uptake $\left(\mathrm{VO}_{2}\right)$, expired carbon dioxide $\left(\mathrm{VCO}_{2}\right)$, and minute ventilation (VE) were averaged for $1 \mathrm{~min}$ during rest, for the entire HVs durations, for 5 breaths immediately after RAST, and for $1 \mathrm{~min}$ after $8 \mathrm{~min} 30 \mathrm{~s}$ of post-RAST recovery. End-tidal $\mathrm{O}_{2}$ partial pressure $\left(\mathrm{PETO}_{2}\right)$ and end-tidal $\mathrm{CO}_{2}$ partial pressure $\left(\mathrm{PETCO}_{2}\right)$ were averaged for $1 \mathrm{~min}$ during rest, for the 5 last breaths during $\mathrm{HV}$, and for the 5 last breaths pre-sprint. During the spontaneous breathing periods between $\mathrm{HV}$, values were averaged for the entire duration. To obtain post-RAST cumulated oxygen uptake $\left(\mathrm{VO}_{2}-\mathrm{OFF}\right)$, cumulated expired carbon dioxide $\left(\mathrm{VCO}_{2}-\mathrm{OFF}\right)$, 
and cumulated ventilation (VE-OFF), breath-by-breath data were cumulated for $9 \mathrm{~min}$ post-sprint and the volumes equivalent to $9 \mathrm{~min}$ at rest (pre-RAST) were subtracted. $\mathrm{PETCO}_{2}$ values were used to estimate $\mathrm{pH}$ levels according to the algorithm of Siggaard-Andersen (Siggaard-Andersen and Siggaard-Andersen, 1990) and to estimate $\mathrm{pH}$ variations according to Dubose's equation (Dubose, 1983): $\mathrm{pH}$ variation $=0.08 \times\left(40-\mathrm{PETCO}_{2}\right.$ measured) / 10.

Apart from during RAST, middle finger pulse oxygen saturation $\left(\mathrm{SpO}_{2}\right)$ was recorded throughout with an oxygen saturation monitor (Pulsox PO-400, Contech Medical Systems, Qinhuangdao, China). Data were averaged for $2 \mathrm{~min}$ during pre-RAST resting, for $5 \mathrm{~s}$ at approximately the highest value during hyperventilation, for $5 \mathrm{~s}$ at approximately the lowest value during breath holds, for the entire duration during the spontaneous breathing intervals in the HV condition, and for the $10 \mathrm{~s}$ pre-RAST.

HR was collected throughout with a thoracic belt and wristwatch (H10 belt and V800 watch, Polar Electro Oy, Kempele, Finland). HR data were filtered using custom routines (MATLAB, the Mathworks, Nattick, MA, USA) with detection and compensation of ectopic beats, median filtering to remove isolated outliers, detection of block errors, and replacement by interpolated values. Data were then averaged over $1 \mathrm{~min}$ during rest, over 5 beats around the lowest value during breath holds in WHBM; over 5 beats around the lowest value during spontaneous breathing periods between hyperventilation periods; over 5 beats around the highest value during hyperventilation; for $750 \mathrm{~s}, 30 \mathrm{~s}, 5$ beats, for the SB, HV, and WHBM conditions, respectively, before RAST; over 5 beats for HR recovery after $1 \mathrm{~min}$; and over 5 beats for HR recovery after 2 min. During RAST, the highest HR was retained as HRmax. HR reserve percentage was calculated using the Karvonen Formula: $H R$ reserve percentage $=(H R \max$ measured during sprints Resting $H R) /(H R$ max predicted - Resting HR), where HRmax predicted was calculated as 220 - age.

\section{Questionnaires}

Prior to each session, the participants completed the Training Distress Scale as a performance readiness assessment (Grove et al., 2014). RPE was recorded on a Borg CR10 scale 1 min after the RAST. A custom questionnaire was used for the subjective assessment of the three sessions. The items were «I felt negative effect(s) of this way of breathing used before the repeated sprint test $\gg:$ yes/no, and if yes, which one(s); «Ifelt positive effect(s) of this way of breathing before the repeated sprint test $\gg$ : yes/no, and if yes, which one(s); «To perform the test, this way of breathing made me feel overall $\gg$ : visual analog scale going from strongly disadvantaged to strongly advantaged; and $\ll$ I plan to reuse this way of breathing in the future in my personal practice $\gg:$ yes/no.

Upon completion of the last session, we added the following additional items: «Rank from 1 to 3 the methods you felt the best in preparation for sprinting ( 1 being the best and 3 being the worst) $\gg$ and «Rank from 1 to 3 the method you think you performed the best with (1 being the best and 3 being the worst) $\gg$. Study data were collected and managed using REDCap electronic data capture tools hosted at UniSanté, Lausanne, Switzerland. An overview of the data collection is shown in Figure 1.

\section{Statistical Analysis}

As no data were available for power calculations since this research was a pilot study, none were performed. For the resting physiological measurements, breathing method physiological measurements, RAST and recovery physiological measurements, and questionnaire results, Shapiro-Wilk's test was used to ensure variable normality. If normality was ensured, condition effects were analyzed using linear mixed models (participants as the random effect and condition as a fixed effect) in two steps. First, to exclude period and carry-over effects of the cross-over trial, we included the effect of time or sequence (fixed effects) as an addition to the model. When time and sequence had no effect, they were removed in the second step. There was a sequence effect for HR at pre-sprint and for the respiratory frequency at rest, and a time effect for VE at HV1. Thus, they were considered in the second step. Normality was not found for Fatigue Index (WHBM condition), for resting $\mathrm{PETCO}_{2}$ (WHBM condition), for resting $\mathrm{VCO}_{2}$ (SB and $\mathrm{HV}$ condition), for $\mathrm{VCO}_{2}$ at $\mathrm{HV} 1$ (SB condition), for $\mathrm{VCO}_{2}$ at $\mathrm{HV} 2$ ( $\mathrm{SB}$ condition), for $\mathrm{VCO}_{2}$ at $\mathrm{HV} 3$ ( $\mathrm{SB}$ and $\mathrm{HV}$ condition), for $\mathrm{VCO}_{2}$ post recovery (SB condition), for $\mathrm{VCO}_{2}$-OFF (SB condition), and for visual analogic scale $\ll$ To perform the test, this way of breathing made me feel overall $\gg$ (SB condition). A non-parametric repeated measures analysis (Friedman test) was performed for these variables. Statistical tests were corrected for multiple comparisons using Bonferroni correction. While these tests were performed using SPSS, version 26 (IBM Corp., Armonk, NY, USA), repeated measures correlation tests were performed between $\mathrm{VCO}_{2}$-OFF and subjective variables with rmcorr library of R version 4.0.5 (R Foundation for Statistical Computing, Vienna, Austria). For all tests, significance was set at $p \leq 0.05$.

\section{RESULTS}

Checking of respect for the protocol, the temperature records, and the performance readiness survey results assured that the experiments occurred in reliable and valid conditions. Due to data recording errors, $\mathrm{SpO}_{2}$ was not saved for two participants in the WHBM condition and respiratory parameters were not saved for one participant in the SB condition.

\section{Feasibility and Performance}

Out of 16 participants, 1 participant was excluded because of a muscular injury (in the lower limb during the first sprint), resulting in a final sample size of 15 . The participants were able to perform the WHBM and HV methods without difficulties. Only minor malfunctions or technical problems occurred during data collection. As described in the section Surveys, $47 \%$ of the participants asserted to use the WHBM in the future while 53\% did not. The values of RAST peak power, average power, and FI are shown in Table 1. There were no significant differences between conditions. 
TABLE 1 | Performances determined during the repeated ability sprint test (RAST) realized with SB, HV, and WHBM conditions.

\begin{tabular}{|c|c|c|c|c|}
\hline & SB & HV & WHBM & $p$ \\
\hline Peak power (watts) & $501.9 \pm 104.5$ & $492.3 \pm 112.7$ & $501.3 \pm 115.6$ & 0.720 \\
\hline Average power (watts) & $418.2 \pm 84.3$ & $407.6 \pm 85.8$ & $413.6 \pm 86.7$ & 0.360 \\
\hline Fatigue index & $4.6 \pm 2.2$ & $4.7 \pm 2.2$ & $4.9 \pm 1.7$ & 0.819 \\
\hline
\end{tabular}

SB, spontaneous breathing; HV, hyperventilation; WHBM, Wim Hof Breathing Method.

Mean values \pm standard deviations.

TABLE 2 | Resting values in SB, HV, and WHBM conditions.

\begin{tabular}{|c|c|c|c|c|}
\hline & SB & HV & WHBM & $p$ \\
\hline HR (bpm) & $75 \pm 10$ & $77 \pm 10$ & $79 \pm 12$ & 0.122 \\
\hline $\mathrm{SpO}_{2}(\%)$ & $96 \pm 1$ & $96 \pm 1$ & $96 \pm 1$ & 0.298 \\
\hline $\mathrm{PETO}_{2}(\mathrm{mmHg})$ & $102 \pm 3$ & $102 \pm 5$ & $103 \pm 5$ & 0.570 \\
\hline $\mathrm{PETCO}_{2}(\mathrm{mmHg})$ & $42 \pm 7$ & $40 \pm 3$ & $40 \pm 4$ & 0.167 \\
\hline $\mathrm{VO}_{2}(\mathrm{ml} / \mathrm{min})$ & $366 \pm 36$ & $364 \pm 70$ & $400 \pm 63$ & 0.119 \\
\hline $\mathrm{VCO}_{2}(\mathrm{ml} / \mathrm{min})$ & $414 \pm 54$ & $403 \pm 105$ & $449 \pm 90^{\ddagger}$ & 0.017 \\
\hline VE (L/min) & $11.2 \pm 1.4$ & $11.4 \pm 2.8$ & $12.7 \pm 2.0^{\dagger}$ & 0.025 \\
\hline Tidal volume (mL) & $1068 \pm 288$ & $1123 \pm 383$ & $1174 \pm 287$ & 0.595 \\
\hline Respiratory frequency (/min) & $12 \pm 4$ & $11 \pm 3$ & $12 \pm 3$ & 0.881 \\
\hline
\end{tabular}

SB, Spontaneous Breathing; HV, Hyperventilation; WHBM, Wim Hof breathing method.

Mean values \pm standard deviations.

tSignificantly greater than SB.

¥ Significantly greater than HV. Bold values indicate significant differences.

\section{Resting Physiological Measurements}

Resting values are presented in Table 2. A significant difference was found in VE between SB and WHBM conditions $(p=0.039)$ and in $\mathrm{VCO}_{2}$ between $\mathrm{HV}$ and WHBM conditions. According to the algorithm of Siggaard-Andersen (Siggaard-Andersen and Siggaard-Andersen, 1990), $\mathrm{PETCO}_{2}$ values indicated resting $\mathrm{pH}$ values of $7.380,7.397,7.397$ for the SB, HV, and WHBM conditions, respectively.

\section{Breathing Method Physiological Measurements}

Table 3 presents $\mathrm{HR}$ max, $\mathrm{SpO}_{2}$ max, $\mathrm{PETO}_{2}$ max, $\mathrm{PETCO}_{2}$ min, average $\mathrm{VO}_{2}$, average $\mathrm{VCO}_{2}$, average $\mathrm{VE}$, average tidal volume, and average respiratory frequency during the hyperventilation periods for the WHBM condition. It further lists $\mathrm{HR}$ min, $\mathrm{SpO}_{2}$ min, and $\mathrm{BH}$ duration during the $\mathrm{BH}$ periods. For the $\mathrm{HV}$ condition, the same parameters during the hyperventilation periods are shown; HR min and averaged values for the other parameters during the spontaneous breathing periods between the hyperventilation periods are also shown. Pre-sprint values are presented for both conditions.

The single inhalation to TLC following breath holding at RV to breaking point generally induced a sharp increase of HR. HR then decreased again during the $15 \mathrm{~s}$ additional $\mathrm{BH}$ at TLC. An example of a HR pattern is presented in Figure 2. A strong correlation $(r=-0.731)$ between $\mathrm{BH}$ duration and $\mathrm{SpO}_{2}$ was found (Figure 3). In the WHBM condition, $\mathrm{VO}_{2}$ during $\mathrm{HV} 2$ and $\mathrm{HV} 3$ was $-288 \pm 182 \mathrm{ml}$ and $-437 \pm 207 \mathrm{ml}$, respectively, inferior to assumed $\mathrm{VO}_{2}$ consumption during the respective previous $\mathrm{BH}$ (resting $\mathrm{VO}_{2} \times \mathrm{BH}$ duration). Assuming no net change in blood buffer status, according to the algorithm of Siggaard-Andersen (Siggaard-Andersen and Siggaard-Andersen, 1990), the minimal $\mathrm{PETCO}_{2}$ values reached at the end of HV3 corresponded to a $\mathrm{pH}$ of 7.651 in the WHBM condition and 7.688 in the HV condition, confirming a state of respiratory alkalosis. The pre-RAST value for the HV condition corresponded to a $\mathrm{pH}$ 7.559 , suggesting partial correction of the respiratory alkalosis. Similarly, according to Dubose's equation (Dubose, 1983), the minimal $\mathrm{PETCO}_{2}$ reached at the end of $\mathrm{HV} 3$ corresponded to a $\mathrm{pH}$ variation of +0.171 units $\mathrm{pH}$ in the WHBM condition and +0.181 in the HV condition. The pre-RAST value for the HV condition corresponded to an increase of +0.123 units $\mathrm{pH}$.

The average values of $\mathrm{VE}, \mathrm{VO}_{2}$, and $\mathrm{VCO}_{2}$ measured at rest, during $\mathrm{HV} 1, \mathrm{HV} 2$, and $\mathrm{HV} 3$, immediately upon arrival after RAST, and during recovery in all three conditions are shown in Figure 4.

\section{RAST and Recovery Physiological Measurements}

Table 4 presents RAST and recovery heart rate. No significant differences were found between the conditions for any of these measurements.

The values of $\mathrm{VE}, \mathrm{VO}_{2}$, and $\mathrm{VCO}_{2}$ measured post-RAST and post-recovery are shown in Figure 4 with VE-OFF, $\mathrm{VO}_{2}-\mathrm{OFF}$, and $\mathrm{VCO}_{2}$-OFF. 
TABLE 3 | Physiological measurements during WHBM and HV conditions.

\begin{tabular}{|c|c|c|c|c|c|c|c|c|c|c|c|}
\hline & & $\begin{array}{l}\text { HR } \\
\text { (bpm) }\end{array}$ & $\begin{array}{c}\mathrm{SpO}_{2} \\
(\%)\end{array}$ & $\begin{array}{c}\mathrm{PETO}_{2} \\
(\mathrm{mmHg})\end{array}$ & $\begin{array}{l}\mathrm{PETCO}_{2} \\
(\mathrm{mmHg})\end{array}$ & $\begin{array}{c}\mathrm{VO}_{2} \\
(\mathrm{ml} / \mathrm{min})\end{array}$ & $\begin{array}{c}\mathrm{VCO}_{2} \\
(\mathrm{ml} / \mathrm{min}]\end{array}$ & $\begin{array}{c}\text { VE } \\
(\mathrm{L} / \mathrm{min})\end{array}$ & $\begin{array}{l}\text { Tidal volume } \\
\text { (ml) }\end{array}$ & $\begin{array}{l}\text { Respiratory } \\
\text { frequency } \\
\text { (1/) }\end{array}$ & $\begin{array}{l}\text { BH duration } \\
\text { (s) }\end{array}$ \\
\hline \multirow[t]{7}{*}{ WHBM condition } & $\mathrm{HV} 1$ & $110 \pm 13.2$ & $99 \pm 0$ & $128 \pm 2$ & $22 \pm 3$ & $501 \pm 79$ & $1344 \pm 213$ & $61.9 \pm 9.2$ & $3148 \pm 537$ & $25 \pm 19$ & - \\
\hline & $\mathrm{BH} 1$ & $67 \pm 15$ & $77 \pm 9$ & - & - & - & - & - & - & - & $74 \pm 16$ \\
\hline & HV2 & $108 \pm 14$ & $99 \pm 0$ & $128 \pm 2$ & $20 \pm 3$ & $673 \pm 128$ & $1179 \pm 181$ & $61.2 \pm 10.9$ & $3135 \pm 553$ & $20 \pm 2$ & - \\
\hline & $\mathrm{BH} 2$ & $67 \pm 1$ & $68 \pm 10$ & - & - & - & - & - & - & - & $101 \pm 19$ \\
\hline & HV3 & $108 \pm 16$ & $99 \pm 1$ & $128 \pm 2$ & $19 \pm 3$ & $730 \pm 129$ & $1112 \pm 201$ & $61.4 \pm 13.3$ & $3112 \pm 773$ & $22 \pm 8$ & - \\
\hline & $\mathrm{BH} 3$ & $66 \pm 14$ & $60 \pm 12$ & - & - & - & - & - & - & - & $119+26$ \\
\hline & Pre-sprint & $\begin{array}{c}80 \pm 17 \\
\varnothing\end{array}$ & $\begin{array}{c}62 \pm 12 \\
¥\end{array}$ & - & $\overline{-}$ & - & - & - & - & - & $\begin{array}{l}- \\
¥\end{array}$ \\
\hline \multirow[t]{7}{*}{ HV condition } & $\mathrm{HV} 1$ & $104 \pm 12$ & $99 \pm 1$ & $128 \pm 2$ & $21 \pm 3$ & $488 \pm 89$ & $1308 \pm 208$ & $59.5 \pm 12.8$ & $2979 \pm 672$ & $22 \pm 7$ & - \\
\hline & $\mathrm{SB} 1$ & $71 \pm 12$ & $97 \pm 1$ & $108 \pm 6$ & $30 \pm 2$ & $299 \pm 68$ & $310 \pm 83$ & $11.6 \pm 3.3$ & $1065 \pm 368$ & $12 \pm 3$ & - \\
\hline & HV2 & $104 \pm 13$ & $99 \pm 1$ & $129 \pm 2$ & $18 \pm 2$ & $511 \pm 124$ & $1136 \pm 201$ & $61.6 \pm 14.0$ & $3072 \pm 859$ & $23 \pm 13$ & - \\
\hline & SB2 & $68 \pm 9$ & $98 \pm 1$ & $107 \pm 7$ & $26 \pm 3$ & $292 \pm 75$ & $249 \pm 87$ & $10.8 \pm 4.2$ & $988 \pm 381$ & $12 \pm 3$ & - \\
\hline & HV3 & $102 \pm 12$ & $99 \pm 0$ & $129 \pm 2$ & $17 \pm 3$ & $542 \pm 120$ & $1030 \pm 161$ & $60.9 \pm 13.0$ & $3130 \pm 696$ & $20 \pm 4$ & - \\
\hline & SB3 & $66 \pm 11$ & $98 \pm 1$ & $109 \pm 8$ & $24 \pm 3$ & $329 \pm 82$ & $266 \pm 95$ & $12.8 \pm 5.4$ & $1144 \pm 480$ & $13 \pm 4$ & - \\
\hline & Pre-sprint & $72 \pm 13$ & $97 \pm 2$ & $\begin{array}{c}105 \pm 10 \\
\#\end{array}$ & $\begin{array}{c}25 \pm 4 \\
+\end{array}$ & $411 \pm 111$ & $294 \pm 116$ & $13.5 \pm 5.7$ & $1076 \pm 559$ & $15 \pm 6$ & - \\
\hline
\end{tabular}

SB, spontaneous breathing; HV, hyperventilation; WHBM, Wim Hof breathing method.

Mean values \pm standard deviations.

-, Non available data.

Indicates that, in average, HR significantly increased with the HVs and significantly decreased with the BHs compared to resting values in WHBM condition.

$¥$ Indicates that values were significantly different between $\mathrm{BH} 1, \mathrm{BH} 2$ and $\mathrm{BH} 3$ in WHBM condition.

\#Indicates that values were significantly greater of resting value in HV1, HV2 and HV3 in HV condition.

tIndicates that pre-sprint value was significantly greater than HV3 in HV condition.

FIndicates that values were significantly different between HV1 and HV2, and between HV1 and HV3 in WHBM condition. 


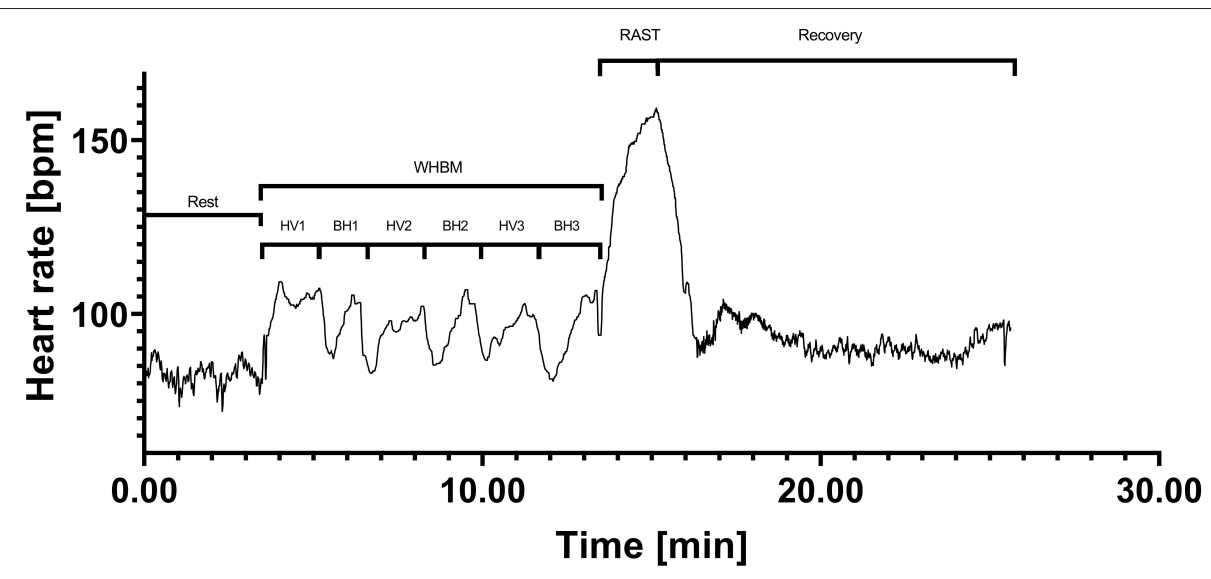

FIGURE 2 | Participant 7 heart rate (HR) data in the Wim Hof breathing method (WHBM) condition.

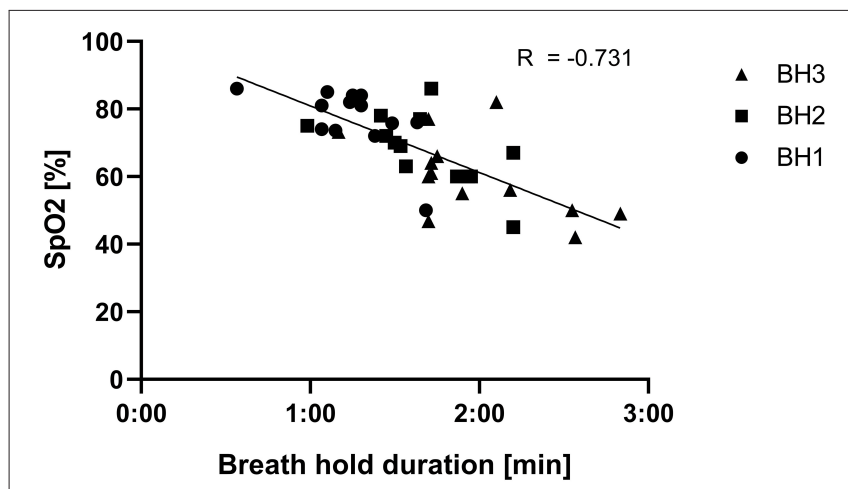

FIGURE 3 | Relation between breath hold durations following hyperventilations (HVs) and oxygen saturation (SpO2) in the Wim Hof breathing method (WHBM) condition.

\section{Surveys}

RAST Borg CR10 scores were $7.5 \pm 1.2,7.6 \pm 1.1$, and $6.9 \pm 1.4$ in SB, HV, and WHBM conditions, respectively. Statistical differences were found for WHBM condition versus $\mathrm{HV}(p=0.008)$ and versus SB condition $(p=0.017)$.

Negative effects of tingling, numbness, dizziness, and heaviness were reported by $60 \%$ of the participants for the HV condition. Negative effects of heaviness and deafness were reported by $33 \%$ of participants for the WHBM. Positive effects of improved breathing and less fatigue were reported by $73 \%$ of the participants for the HV condition. Positive effects of improved breathing, less fatigue, and increased energy were reported by $87 \%$ of the participants for the WHBM condition. Finally, $47 \%$ reported planning to reuse the WHBM in their personal training and competitive practice in the future while $53 \%$ declared not to.

Participants felt the most advantaged when performing the test in the WHBM condition, followed by the HV condition (Figure 5). A significant difference was found between WHBM and SB conditions.
Overall assessment of the breathing methods provided the results shown in Table 5. A majority of participants assessed WHBM as the best and SB as the worst.

\section{DISCUSSION}

\section{Feasibility and Performance}

This study reports the feasibility and effects of practicing the WHBM before repeated sprinting performance. The acute effects of a single session of WHBM were assessed on repeatedsprint bouts and on various physiological and psychological variables. After receiving anecdotal information from early adopters, we expected that the use of WHBM might give an edge for sprinting performance. Participants consented to comply and adequately performed the WHBM and procedures, contributing to a valid assessment. Despite some lightheadedness and tingling, they were able to perform the RAST as required. However, in spite of large physiological effects of both $\mathrm{HV}$ and WHBM, no significant condition effect was found regarding performance, peak power, average power, or fatigue index. Apart from the $\mathrm{CO}_{2}$ stores depletion that persisted through the RAST $\left(\mathrm{VCO}_{2}-\mathrm{OFF}\right)$, the observed physiological effects were specific and immediate to the respiratory maneuvers, and they did not translate into global physiological repercussions that could change performance. It follows that, despite subjective preference for the two breathing methods in comparison with spontaneous breathing, in the present experimental conditions, the acute application of two specific breathing methods did not convey any advantage for repeated sprinting performance as assessed with the RAST. However, the lower post-sprint $\mathrm{CO}_{2}$ levels in $\mathrm{HV}$ and WHBM conditions could be a factor that explains the subjective preference. Indeed, $\mathrm{VCO}_{2}$ levels are linked to respiratory distress in dyspnea and apnea studies. Although weak, a correlation between $\mathrm{VCO}_{2}$-OFF and the survey item «Rank from 1 to 3 the method you think you performed the best with $\gg$ was found $(r=-0.445, p=0.014)$. However, the subjective preference could also reflect some placebo mechanism. 
A

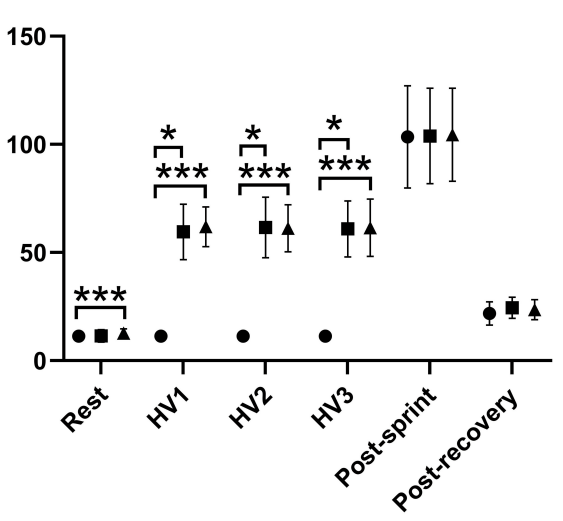

C

$\mathrm{VO}_{2}[\mathrm{~mL} / \mathrm{min}]$

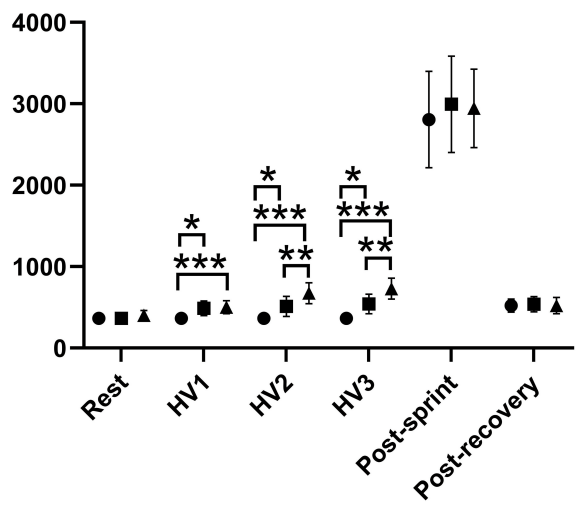

E

$\mathrm{VCO}_{2}[\mathrm{~mL} / \mathrm{min}]$

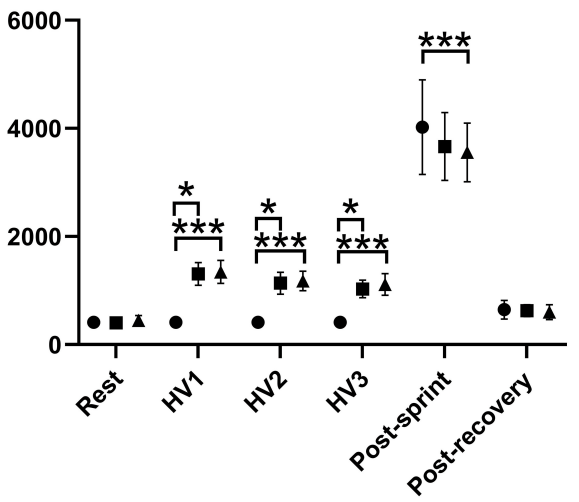

VE OFF [L]

- $\mathrm{SB}$

- HV

- WHBM

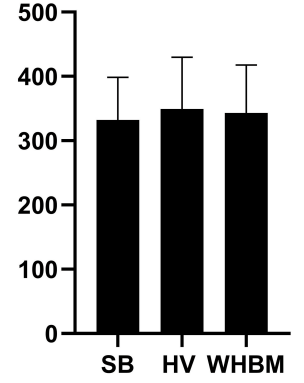

D

$\mathrm{VO}_{2}$ OFF [L]

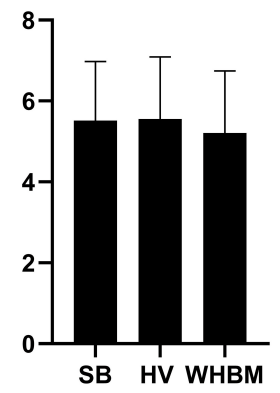

F

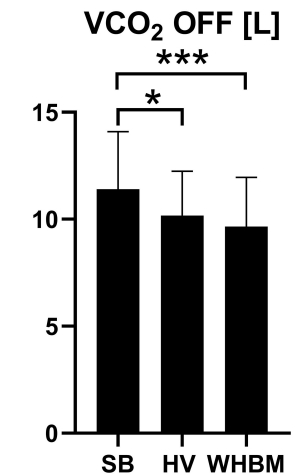

FIGURE 4 | (A) Changes in minute ventilation (VE), (B) cumulated ventilation (VE-OFF), (C) oxygen uptake $\left(\mathrm{NO}_{2}\right)$, (D) cumulated oxygen uptake $(\mathrm{VO} 2$-OFF), (E) expired carbon dioxide $\left(\mathrm{VCO}_{2}\right)$, and $(\mathbf{F})$ cumulated expired carbon dioxide $\left(\mathrm{VCO}_{2}-\mathrm{OFF}\right)$ for $\mathrm{SB}, \mathrm{HV}$ and WHBM conditions. SB, spontaneous breathing; $\mathrm{HV}$, hyperventilation; WHBM, Wim Hof Breathing Method. *indicates a significant difference between SB and HV condition, ${ }^{*}$ indicates significant difference between HV and WHBM condition, ${ }^{\star \star *}$ indicates significant difference between SB and WHBM condition.

\section{Respiratory Alkalosis}

$\mathrm{PETCO}_{2}$ values indicated a blood $\mathrm{pH}$ increase of +0.171 (to reach an estimated $\mathrm{pH}$ of 7.651) upon the last $\mathrm{HV}$ in the WHBM condition, which could have had ergogenic effects on anaerobic performance by preventing and/or compensating exercise-induced metabolic acidosis (Jacob et al., 2008). However, in the WHBM condition, the $\mathrm{HV}$-induced respiratory alkalosis was attenuated by the ensuing $\mathrm{BH}$-induced $\mathrm{CO}_{2}$ retention. 
TABLE 4 | Repeated ability sprint test (RAST) and recovery heart rate during WHBM and HV conditions.

\begin{tabular}{|c|c|c|c|c|}
\hline & SB & HV & WHBM & $p$ \\
\hline Pre-sprint (bpm) & $76 \pm 8$ & $72 \pm 13$ & $80 \pm 17$ & 0.083 \\
\hline Highest HR during sprint (bpm) & $173 \pm 8$ & $172 \pm 7$ & $173 \pm 8$ & 0.122 \\
\hline Highest percentage of HR reserve during sprints (\%) & $81 \pm 7$ & $80 \pm 7$ & $80 \pm 7$ & 0.063 \\
\hline HR recovery after 1 min (bpm) & $-49 \pm 14$ & $-48 \pm 10$ & $-48 \pm 13$ & 0.755 \\
\hline HR recovery after 2 min (bpm) & $-62 \pm 9$ & $-62 \pm 9$ & $-61 \pm 10$ & 0.477 \\
\hline
\end{tabular}

SB, spontaneous breathing; HV, hyperventilation; WHBM, Wim Hof breathing method.

Mean values \pm standard deviations. HR recovery values indicate post exercise drops in HR from highest HR during sprint, in bpm.

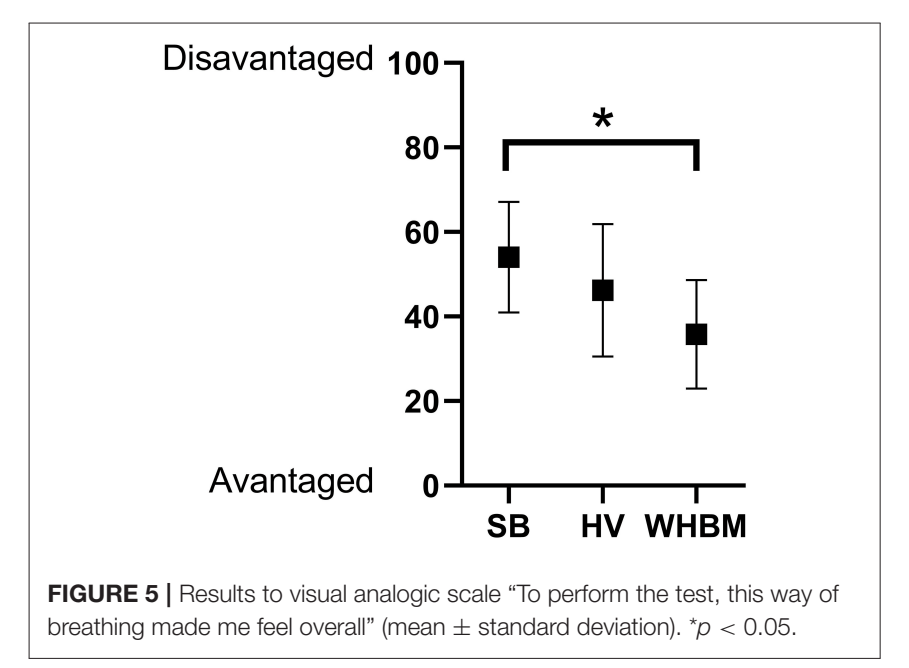

Indeed, $\mathrm{PETCO}_{2}$ values decreased along the $\mathrm{HV}$ s to a lower level in $\mathrm{HV}$ compared to the WHBM condition (down to $17 \pm 3$ versus $19 \pm 3 \mathrm{mmHg}$, respectively). This difference was not significant, but it can be hypothesized that it increased slightly with the last $\mathrm{BH}$. Additionally, HVs effects were probably also attenuated during the delay before the RAST. In the HV condition, $\mathrm{PETCO}_{2}$ rose pre-sprint to values that corresponded to a $+0.123 \mathrm{pH}$ change (and an estimated $\mathrm{pH}$ of 7.564) instead of +0.181 (and a $\mathrm{pH}$ of 7.682)] at the end of the last HV. Thus, we speculate that the WHBM pH change was slightly inferior to +0.123 before beginning the RAST. In agreement, another study on WHBM reported that a representative subject ended the last $\mathrm{BH}$ with a $\mathrm{pH}$ of 7.50, a value 0.10 higher than at the start (Kox et al., 2014). In comparison, other studies reported improved performance using $\mathrm{HV}$ with comparable or smaller $\mathrm{pH}$ changes (Sakamoto et al., 2014; Jacob et al., 2015), greater pH changes (Ziegler, 2002), and smaller $\mathrm{pH}$ changes using bicarbonate supplementation (Costill et al., 1984; Bishop et al., 2004). However, other studies did not find improved performance even though comparable or smaller pH changes were reported (Jacob et al., 2008; Kairouz et al., 2013; Sakamoto et al., 2018). While the literature is not unanimous, $\mathrm{HV}$, by inducing respiratory alkalosis, may have positive effects on anaerobic type performance.

\section{Diving Response}

$\mathrm{BH}$ by itself triggers the so-called diving response, and when coupled with stimulation of facial cold receptors, a greater response is seen (Foster and Sheel, 2005). The diving response includes bradycardia, peripherical vasoconstriction, increased blood pressure, and contraction of the spleen (Dujic et al., 2011). Breath-holding is known to induce spleen contraction leading to an increase of blood hemoglobin concentration (Schagatay et al., 2001). Spleen contraction releases stored erythrocytes into the circulation. A single contraction causes a hemoglobin increase that corresponds to a $3-10 \%$ increase in blood oxygen carrying capacity (Stewart and McKenzie, 2002). The increased hemoglobin levels may have potentially beneficial effects on performance for both increased blood $\mathrm{O}_{2}$ carrying capacity and increased $\mathrm{CO}_{2}$ buffering capacity (Schagatay et al., 2012). However, the increased blood pressure and peripheral vasoconstriction might impair performance. Studies evaluating the effect of apneas on performance found no improvement (Du Bois et al., 2014; Sperlich et al., 2015; Yildiz, 2018). In consistence with these studies, the WHBM did not enhance performance in this investigation.

\section{Blood Oxygen Saturation}

Oxygen saturation dropped to very low levels at the end of the BHs $(60 \%)$. The $10 \mathrm{~s}$ delay before the start of RAST might not have allowed full recovery of saturation, which could have impaired performance. In another study assessing an apnea test following a forced expiration, oximetry recovery times were between 20 and $40 \mathrm{~s}$ (Plas and Bourdinaud, 1953).

\section{Catecholamine and Cortisol Levels}

In another investigation (Kox et al., 2014), the authors reported that, while WHBM led to no increase in norepinephrine, dopamine, and cortisol levels, significantly higher plasma epinephrine levels were found. The latter has a powerful vasodilator effect on blood vessels in skeletal muscle (Davis et al., 2008) and stimulates glycogenolysis (Kenney, 2012), which could lead to ergogenic effects in the WHBM condition.

\section{Gas Exchange}

Comparable VE was observed during HVs in the $\mathrm{HV}$ and WHBM conditions. Compared to spontaneous breathing, $\mathrm{VO}_{2}$ showed significantly higher values for the HV condition, which is possibly linked to greater work performed by the respiratory muscles (Coast et al., 1993). VE was further increased in the WHBM condition, likely due to the $\mathrm{BH}$-induced oxygen desaturation leading to a hypoxic ventilatory response (Figure 4C). Intriguingly, the difference in $\mathrm{VO}_{2}$ consumption between the WHBM and $\mathrm{HV}$ conditions during $\mathrm{HV} 2$ and $\mathrm{HV} 3$ was inferior to assumed $\mathrm{VO}_{2}$ consumption during the previous $\mathrm{BH}$. $\mathrm{VCO}_{2}$ showed significantly higher values in the $\mathrm{HV}$ condition as a result of larger $\mathrm{CO}_{2}$ elimination, and it 
TABLE 5 | Overall assessment of breathing methods in percentage of participants.

\begin{tabular}{|c|c|c|c|c|}
\hline & & SB & HV & WHBM \\
\hline \multirow[t]{2}{*}{ The best / the worst method in term of sprint test } & The best & $13.3 \%$ & $13.3 \%$ & $73.3 \%$ \\
\hline & The worst & $53.3 \%$ & $46.7 \%$ & $0.0 \%$ \\
\hline \multirow[t]{2}{*}{ The best / the worst method in term of perceived performance } & The best & $13.3 \%$ & $20.0 \%$ & $66.7 \%$ \\
\hline & The worst & $53.3 \%$ & $46.7 \%$ & $0.0 \%$ \\
\hline
\end{tabular}

rose to an even greater extent in the WHBM condition given the $\mathrm{CO}_{2}$ accumulation during the post-HV BHs. However, this difference was not significant (Figure 4E). $\mathrm{VCO}_{2}$-post after RAST in the WHBM condition was significantly smaller than in the SB condition, while in the HV condition it was not, which is counter-intuitive given the $\mathrm{CO}_{2}$ accumulation during BHs. In addition, it is interesting to note that $\mathrm{VCO}_{2}$-OFF was significantly smaller in both the WHBM and HV conditions than in the SB condition, which suggests that some of the $\mathrm{HV}$-induced $\mathrm{CO}_{2}$ stores depletion had persisted through the RAST.

\section{Breath-Hold Duration}

$\mathrm{BH}$ durations were comparable to the durations most people can achieve with no prior $\mathrm{HV}$ and at full lung volume. We speculate that several factors counterbalanced each other, resulting in these durations. The most potent regulator of ventilatory drive is $\mathrm{pH}$, followed by partial pressure of carbon dioxide $\left(\mathrm{PCO}_{2}\right)$, and, to a lesser extent, partial pressure of oxygen $\left(\mathrm{PO}_{2}\right)$ (Saladin and Miller, 2004). There is also a substantial prolongation of $\mathrm{BH}$ time that is independent of chemical stimuli, which has been attributed to neural input from pulmonary stretch receptors (Mithoefer et al., 1953). Thus, apnea at low lung volume as performed in WHBM leads to shorter BHs because of the decreased stimulus to the pulmonary stretch receptors and accelerated onset of hypoxia and hypercapnia (decreased $\mathrm{O}_{2}$ pulmonary volume and decreased capability to dilute the rise in metabolically-derived $\mathrm{CO}_{2}$ levels) (Skow et al., 2015). However, considering that $\mathrm{HV}$ reduces arterial $\mathrm{CO}_{2}$ content and increases arterial $\mathrm{pH}$, the subsequent $\mathrm{BH}$ duration should be longer, as it will take longer to reach the threshold of chemoreceptor activation (Skow et al., 2015). Consistent with previous findings (Schagatay et al., 1999), the latter is also the more likely reason as to why $\mathrm{BH}$ duration significantly increased between sets: the successive HVs progressively reduced arterial $\mathrm{PCO}_{2}$ as suggested by the decreasing $\mathrm{PETCO}_{2}$ values from one to the other $\mathrm{HV}$. Under such conditions, arterial $\mathrm{PO}_{2}$ can decrease to a greater extent (Djarova et al., 1986) and trigger spleen contraction as described above. In this study, oxygen saturation dropped progressively through the $\mathrm{BH}$ sets and reached severe hypoxemia levels $(60 \%)$ at the end of the last $\mathrm{BH}$, which is consistent with another WHBM investigation where values reportedly even decreased to about 50\% (Kox et al., 2014). The correlation between $\mathrm{SpO}_{2}$ and $\mathrm{BH}$ duration (Figure 2) further illustrates the above explanations. In $\mathrm{BHs}$ following $\mathrm{HV}$, activation of the peripheral chemoreceptors from sensing increased $\mathrm{CO}_{2}$ is delayed, and their activation from sensing decreased $\mathrm{O}_{2}$ is increased. If $\mathrm{SpO}_{2}$ decreased to a great extent during $\mathrm{BHs}$, it resumed normal values during the HVs, i.e., almost fully saturated (Kenney et al., 2012). Consistent with these studies, $\mathrm{PETO}_{2}$ significantly increased above resting value during HV1, HV2, and HV3 in this study, indicating the effect of hyperventilation on alveolar gas composition.

\section{Heart Rate}

In the WHBM condition, HR significantly increased (by $31 \mathrm{bpm}$ on average) during the HVs and significantly decreased (by 13 $\mathrm{bpm}$ on average) during the $\mathrm{BH}$ s compared to resting values. The $\mathrm{HR}$ increases during HVs were probably due to increased motor drive for increased respiratory muscle activity (Cummin et al., 1986). The HR drops during the BHs are generally attributed to an increase in cardiac parasympathetic drive triggered in response to breathing cessation (Cherouveim et al., 2013). However, the HR drops were also observed in the HV condition; thus, HV cessation may be the main explanation. The sharp HR increase following the first inhalation after BHs observed in this study has been previously described. Upon resumption of breathing after an apnea test following forced expiration, pulses give way sometimes to an irregular acceleration, which tends to stabilize quickly (10-15s) at approximately its initial rate (Plas and Bourdinaud, 1953). Because of these mechanisms, pre-sprint HR was not significantly different between conditions. During the sprints, HR reserve percentage reached testified to the high intensity of the effort.

\section{Surveys}

Psychological assessment showed rather positive results in the WHBM condition; RPE was significantly the lowest, participants felt significantly advantaged the most to perform the test, and felt the best for doing the sprint test and thought they performed the best. Around three-quarters of them reported positive effects such as less fatigue, increased energy, and improved breathing. Speculatively, the latter could potentially be due to reduced work of breathing resulting from pre-activation of sympathetic drive and catecholamine secretion, leading to bronchodilation and decreased airflow resistance (Sakamoto et al., 2014). On the other hand, negative effects such as deafness or dizziness were reported, potentially caused by the HV induced hypocapnia causing cerebral vasoconstriction (Skow et al., 2015). In the end, around half of our participants declared that they would consider the WHBM in their personal practice in the future. The participants reported significantly lower RPE with the WHBM. This may be due to a lesser "maximality" of the sprinting effort or reflect some placebo mechanism. The participants were necessarily aware that the experiment aimed to assess the effects 
of two breathing methods on repeated sprinting performance. Their belief that the WHBM might be beneficial could have led to such results or even worse, it may even have negated a decreased performance from WHBM-induced changes in physiological variables such as $\mathrm{SpO}_{2}$.

\section{Limitations}

Several limitations should be considered when interpreting the results of this research. First, the relatively small sample size affected the reliability of the study. Second, because one is supposed to do a deep inspiration from RV to TLC $15 \mathrm{~s}$ before the end of the $\mathrm{BH}$ in WHBM and arterial blood gas analysis was not feasible, it was not possible to document pulmonary or blood gas exchanges during and at the end of the WHBM $\mathrm{BHs}$. Also, there are several studies in the literature expressing reservations about the reliability of $\mathrm{SpO}_{2}$ in situations leading to deep hypoxemia (Pottecher et al., 2003), indicating that the $\mathrm{SpO}_{2}$ results during the $\mathrm{BHs}$ should be interpreted with caution. Third, fatigue index values were rather low compared to other studies: 7.1 in students of physical education and sport exercise (Paradisis et al., 2005), 5.4 after a power endurance training in basketball players (Balčiunas et al., 2006), 8.1-10.5 in elite basketball players (Pojskić et al., 2015), 4.2 in football players, 4.2 in sprinters, 4.2 in takrawer, 2 in volleyballers, and 4.6 in Pencak Silater athletes (Nasuka et al., 2019). The results could have been different if the participants had reached higher FI. A sensitivity analysis in this study on the four participants with a FI superior to five did not show statistical differences either. Finally, the participants described starting the RAST after resting motionless for $\sim 12 \mathrm{~min}$ in a supine position as difficult. Vigorous respiratory muscle contraction in the WHBM and HV conditions and maximal apnea in the WHBM condition could have mitigated these negative effects.

Another investigation could evaluate using the WHBM sitting on a chair or standing to limit the difficulty previously mentioned even if it would involve a less optimal breathing position. It would also be interesting to assess effects of apnea followed by HV, as potential ergogenic apnea-induced spleen contraction could last long enough and potential ergogenic HV-induced effects would be optimized if exercise was performed without delay. Moreover, while this study focused on acute effects of the WHBM, it would be of interest to assess its regular use in combination with training. Repeated-sprint training in hypoxia has been shown to induce greater improvement of repeated-sprint performance than in normoxia (Brocherie et al., 2017). Also, repeated sprintinduced arterial desaturation through voluntary hypoventilation at low lung volume induced greater enhancement in competitive

\section{REFERENCES}

Balčiunas, M., Stonkus, S., Abrantes, C., and Sampaio, J. (2006). Long term effects of different training modalities on power, speed, skill and anaerobic capacity in young male basketball players. J. Sports Sci. Med. 5, 163-170.

Bishop, D., Edge, J., Davis, C., and Goodman, C. (2004). Induced metabolic alkalosis affects muscle metabolism and repeated-sprint ability. Med. Sci. Sports Exerc. 36, 807-813. doi: 10.1249/01.MSS.0000126392.20025.17 swimmers than in normoxia (Trincat et al., 2017), and the magnitude of the improvement $(+35 \%)$ was comparable to that obtained with repeated sprinting in hypoxia in cycling $(+38 \%)$ (Faiss et al., 2013) and in double poling cross-country skiing $(+58 \%)$ (Faiss et al., 2015). Similar or even greater improvements might be expected with a regular use of the WHBM.

\section{PRACTICAL APPLICATIONS}

This investigation is the first to evaluate the WHBM in view of improving repeated sprinting performance. While this pilot study underlined the possibility of practicing an acute session of WHBM before sport performance, it also presented side effects and did not enhance any performance parameter (peak power, average power, and FI) in later sprint sets. It appears unworthy to carry this method out as the improved physiological parameters did not translate into a performance increase. Based on the results found in this study, we do not recommend applying this method with the view of improving performance, at least not for repeated sprinting.

\section{DATA AVAILABILITY STATEMENT}

The raw data supporting the conclusions of this article will be made available by the authors, without undue reservation.

\section{ETHICS STATEMENT}

The studies involving human participants were reviewed and approved by Research Ethics Committee of the Canton Vaud. The patients/participants provided their written informed consent to participate in this study.

\section{AUTHOR CONTRIBUTIONS}

KG, BK, FC, and TC: conception and design, analysis and interpretation of data, drafting the article, critically revising the article, and final approval of the article. TC and KG: acquisition of data. All authors contributed to the article and approved the submitted version.

\section{ACKNOWLEDGMENTS}

The authors would like to acknowledge the participants for their participation and commitment to the project. 
consumption during exercise and hyperventilation. J. Appl. Physiol. 74, 793-798. doi: 10.1152/jappl.1993.74.2.793

Costill, D. L., Verstappen, F., Kuipers, H., Janssen, E., and Fink, W. (1984). Acidbase balance during repeated bouts of exercise: influence of $\mathrm{HCO}_{3}$. Int. J. Sports Med. 5, 228-231. doi: 10.1055/s-2008-1025910

Cummin, A. R., Iyawe, V. I., Mehta, N., and Saunders, K. B. (1986). Ventilation and cardiac output during the onset of exercise, and during voluntary hyperventilation, in humans. J. Physiol. 370, 567-583. doi: 10.1113/jphysiol.1986.sp015951

Davis, E., Loiacono, R., and Summers, R. J. (2008). The rush to adrenaline: drugs in sport acting on the $\beta$-adrenergic system. Br. J. Pharmacol. 154, 584-597. doi: 10.1038/bjp.2008.164

Djarova, T., Ilkov, A., Varbanova, A., Nikiforova, A., and Mateev, G. (1986). Human growth hormone, cortisol, and acid-base balance changes after hyperventilation and breath-holding. Int. J. Sports Med. 7, 311-315. doi: 10.1055/s-2008-1025782

Du Bois, A. M., Nelson, G. C., Ciccone, A. B., April, S. M., Thurston, T. S., Brown, L. E., et al. (2014). Effect of serial apneas and facial immersion on high intensity aerobic performance. Med. Sci. Sports Exerc. 46, 701-701. doi: 10.1249/01.mss.0000495581.06853.6c

Dubose, T. (1983). Clinical approach to patients with acid-base disorders. Med. Clin. North Am. 67, 799-813. doi: 10.1016/S0025-7125(16)31178-6

Dujic, Z., Breskovic, T., and Ljubkovic, M. (2011). Breath hold diving: in vivo model of the brain survival response in man? Med. Hypotheses 76, 737-40. doi: 10.1016/j.mehy.2011.02.012

Faiss, R., Léger, B., Vesin, J.-M., Fournier, P.-E., Eggel, Y., Dériaz, O., et al. (2013). Significant molecular and systemic adaptations after repeated sprint training in hypoxia. PLos ONE 8:e56522. doi: 10.1371/journal.pone.00 56522

Faiss, R., Willis, S., Born, D.-P., Sperlich, B., Vesin, J.-M., Holmberg, H.-C. and Millet, G. P. (2015). Repeated double-poling sprint training in hypoxia by competitive cross-country skiers. Med. Sci. Sports Exerc. 47, 809-17. doi: 10.1249/MSS.0000000000000464

Foster, G. E., and Sheel, A. W. (2005). The human diving response, its function, and its control. Scand. J. Med. Sci. Sports 15, 3-12. doi: 10.1111/j.1600-0838.2005.00440.x

Grove, J. R., Main, L. C., Partridge, K., Bishop, D. J., Russell, S., Shepherdson, A., et al. (2014). Training distress and performance readiness: laboratory and field validation of a brief self-report measure. Scand. J. Med. Sci. Sports 24, e483-e490. doi: 10.1111/sms.12214

Hof, W. (2020a). The Wim Hof Method: Activate Your Full Human Potential. Boulder, CO: Sounds True.

Hof, W. (2020b). The Benefits of Breathing Exercises|Wim Hof Method. Available online at: https://www.wimhofmethod.com/breathing-exercises (accessed April 22, 2020).

Hof, W. (2020c). The History of the 'Iceman' Wim Hof|Wim Hof Method. Available online at: https://www.wimhofmethod.com/iceman-wim-hof (accessed November 24, 2020).

Hof, W. (2020d). Training for Improved Sports Performance|Wim Hof Method. Available online at: https://www.wimhofmethod.com/sports-performancetraining (accessed November 26, 2020).

Hof, W. (2020e). Welcome to the Official Wim Hof Method Website. Available online at: https://www.wimhofmethod.com/ (accessed November 24, 2020).

Hof, W. (2021). Faster Workout Recovery|Wim Hof Method. Available online at: https://www.wimhofmethod.com/workout-recovery (accessed February 11, 2021).

Jacob, C., Keyrouz, C., Bideau, N., Nicolas, G., El Hage, R., Bideau, B., et al. (2015). Pre-exercise hyperventilation can significantly increase performance in the 50-meter front crawl. Sci. Sports 30, 173-176. doi: 10.1016/j.scispo.2015. 02.006

Jacob, C., Moussa, E., Keyrouz, C., and Zouhal, H. (2008). Effet d'une hyperventilation volontaire préexercice sur la performance lors de l'épreuve de Wingate. Sci. Sports 23, 83-86. doi: 10.1016/j.scispo.2007. 09.012

Kairouz, C., Jacob, C., El Hage, R., Khoury, G., Moussa, E., and Zouhal, H. (2013). Effect of hyperventilation followed by a $1 \mathrm{~min}$ recovery on the wingate performance. Sci. Sports 28, e15-18. doi: 10.1016/j.scispo.2012. 08.001
Kelly Slater's Bizarre, Daredevil-Inspired Breathing Technique (2021). Available online at: http://www.surfline.com/surf-news/the-11x-world-champion-ispracticing-mystic-mental-exercises-from-iceman-wim-hof-kelly-slatersbizarre-daredev_139041/(accessed February 11, 2021).

Kenney, W. L. (2012). Hormonal control during exercise. Physiology of Sport and Exercise, 5th ed. (Champaign, IL: Human Kinetics), 92-110.

Kenney, W. L., Wilmore, J. H., and Costill, D. L. (2012). Cardiorespiratory Responses to Acute Exercise. Physiology of Sport and Exercise, 5th ed. (Champaign, IL: Human Kinetics), 182-204.

Kox, M., van Eijk, L.T., Zwaag, J., van den Wildenberg, J., Sweep, F. C. G. J., and van der Hoeven, J. G. (2014). Voluntary activation of the sympathetic nervous system and attenuation of the innate immune response in humans. Proc. Natl. Acad. Sci. U.S.A. 111, 7379-7384. doi: 10.1073/pnas.1322 174111

Mithoefer, J.C., Stevens, C.D., Ryder, H.W., and McGuire, J. (1953). Lung volume restriction, hypoxia and hypercapnia as interrelated respiratory stimuli in normal man. J. Appl. Physiol. 5, 797-802. doi: 10.1152/jappl.1953.5. 12.797

Nasuka, Santosa, I., Setiowati, A., and Indrawati, F. (2019). The running-based anaerobic sprint test of different type of sports. J. Phys. Conf. Ser. 1387:012146. doi: 10.1088/1742-6596/1387/1/012146

Nick, D., and Whyte, G. (1997). Anaerobic Performance Testing. Peak Performance 87, 7-9.

Novak Djokovic on Instagram: @iceman_hof how did we do?... (2021). Available online at: https://www.instagram.com/tv/B8yBldEnTOx/?utm_source=ig_ embed (accessed April 26, 2021).

Paradisis, G., Tziortzis, S., Zacharogiannis, E., Smirniotoy, A., and Karatzanos, E. (2005). Correlation of the running-based anaerobic sprint test (RAST) and performance on the $100 \mathrm{M}, 200 \mathrm{M}$ and $400 \mathrm{M}$ distance tests. J. Human Mov. Stud. 49, 77-92.

Pflanzer, R. G. (2004). "The respiratory cycle," in Experimental and Applied Physiology Lab Manual, 7th Edn (Boston, MA: McGraw-Hill Higher Education), 323-336.

Plas, F., and Bourdinaud, J. (1953). Apnea test following forced expiration controlled by Millikan's oxymeter; studies on cardiovascular reactions during the test. La Med. Aeronautique 8, 11-16.

Pojskić, H., Šeparovi,ć, V., UŽičanin, E., Muratovi,ć, M., and Mačković, S. (2015). Positional role differences in the aerobic and anaerobic power of elite basketball players. J. Human Kinet. 49, 219-227. doi: 10.1515/hukin-2015-0124

Pottecher, J., Bouzou, G., and Van de Louw, A. (2003). Monitorage de la saturation de pouls : intérêts et limites. Réanimation 12, 30-36. doi: 10.1016/S1624-0693(02)00006-3

Sakamoto, A., Naito, H., and Chow, C.-M. (2014). Hyperventilation as a strategy for improved repeated sprint performance. J. Strength Condition. Res. 28, 1119-1126. doi: 10.1519/JSC.0b013e3182a1fe5c

Sakamoto, A., Naito, H., and Chow, C-M. (2018). Effects of hyperventilation on repeated pedaling sprint performance: short vs. long intervention duration. J. Strength Condition. Res. 32, 170-80. doi: 10.1519/JSC.0000000000 001789

Saladin, K.S., and Miller, L. (2004). The respiratory system. Anatomy and Physiology: The Unity of Form and Function (Boston: McGraw Hill), 841-874.

Schagatay, E., Andersson, J., Hallén, M., and Pålsson, B. (2001). Selected contribution: role of spleen emptying in prolonging apneas in humans. J. Appl. Physiol. 90, 1623-29. discussion 1606. doi: 10.1152/jappl.2001.90. 4.1623

Schagatay, E., Kampen, M., and Andersson, J. (1999). Effects of repeated apneas on apneic time and diving response in non-divers. Undersea Hyperbaric Med. 26, 143-149.

Schagatay, E., Richardson, M., and Lodin-Sundström, A. (2012). Size matters: spleen and lung volumes predict performance in human apneic divers. Front. Physiol. 3:173. doi: 10.3389/fphys.2012.00173

Siggaard-Andersen, O., and Siggaard-Andersen, M. (1990). The oxygen status algorithm: a computer program for calculating and displaying $\mathrm{PH}$ and blood gas data. Scand. J. Clin. Lab. Investig. 203: 29-45. doi: 10.3109/00365519009087489

Skow, R.J., Day, T.A., Fuller, J.E., Bruce, C.D., and Steinback, C.D. (2015). The ins and outs of breath holding: simple demonstrations of complex respiratory physiology. Adv. Physiol. Educ. 39, 223-231. doi: 10.1152/advan.00030.2015 
Sperlich, B., Zinner, C., Pfister, R., Holmberg, H.-C., and Michels, G. (2015). Repeated apnea-induced contraction of the spleen in cyclists does not enhance performance in a subsequent time-trial. Eur. J. Appl. Physiol. 115, 205-212. doi: 10.1007/s00421-014-3003-x

Stewart, I. B., and McKenzie, D. C. (2002). The human spleen during physiological stress. Sports Med. 32, 361-369. doi: 10.2165/00007256-20023206000002

Trincat, L., Woorons, X., and Millet, G. P. (2017). Repeated-sprint training in hypoxia induced by voluntary hypoventilation in swimming. Int. J. Sports Physiol. Perform. 12, 329-335. doi: 10.1123/ijspp.20150674

Yildiz, M. (2018). The acute effects of repeated static apnea on aerobic power. Phys. Educ. Stud. 22, 217-220. doi: 10.15561/20755279.2018.0407

Zagatto, A., Beck, W., and Gobatto, C. (2008). Validity of the running anaerobic sprint test (Rast) for assess anaerobic power and predicting performances: 2138. Med. Sci. Sports Exerc. 40:S387. doi: 10.1249/01.mss.0000322650.40862.f6

Ziegler, A. (2002). Effect of Hyperventilation on Performance in Wingate Anaerobic Test (PhD Thesis). Freie Universität Berlin.
Conflict of Interest: The authors declare that the research was conducted in the absence of any commercial or financial relationships that could be construed as a potential conflict of interest.

Publisher's Note: All claims expressed in this article are solely those of the authors and do not necessarily represent those of their affiliated organizations, or those of the publisher, the editors and the reviewers. Any product that may be evaluated in this article, or claim that may be made by its manufacturer, is not guaranteed or endorsed by the publisher.

Copyright (c) 2021 Citherlet, Crettaz von Roten, Kayser and Guex. This is an openaccess article distributed under the terms of the Creative Commons Attribution License (CC BY). The use, distribution or reproduction in other forums is permitted, provided the original author(s) and the copyright owner(s) are credited and that the original publication in this journal is cited, in accordance with accepted academic practice. No use, distribution or reproduction is permitted which does not comply with these terms. 